\title{
ASPECTOS PRODUTIVOS DO CAPIM MARANDU SUBMETIDO A ADUBAÇÃO FOSFATADA EM NÍVEIS DE SATURAÇÃO POR BASES
}

\author{
Hugo Valério Moreira Rodrigues ${ }^{1}$, Rubson Costa Leite ${ }^{2 *}$, Gilson Araújo de Freitas ${ }^{1}$, \\ Igo Moreira de Oliveira ${ }^{3}$, Saulo Oliveira Lima ${ }^{1}$
}

\begin{abstract}
RESUMO - Um dos principais problemas para a degradação das pastagens brasileiras é a não correção e reposição de nutrientes do solo, uma vez que essas práticas são comuns na agricultura, no entanto negligenciadas em pastagens. Objetivou-se avaliar o desempenho da forrageira Marandu em doses de adubação fosfatada nos níveis de saturação por bases recomendados para pastagens. O experimento foi conduzido em uma fazenda no município de Gurupi-TO. O delineamento utilizado foi em blocos casualizados, em arranjo fatorial $3 \times 5$, com quatro repetições. Foram avaliadas plantas em doses de adubação fosfatada $(0,30,60,90$ e $120 \mathrm{~kg} / \mathrm{ha}$ de $\mathrm{P}_{2} \mathrm{O}_{5}$ ) nos níveis de saturação por bases $(\mathrm{V} \%$ ) para pastagens (baixo $=35 \%$, adequado $=45 \%$ e alto $=65 \%$ ). As variáveis analisadas foram altura de plantas, número de perfilhos e massa de forragem. Plantas de capim Marandu apresentaram melhor resposta a adubação fosfatada em maiores níveis de saturação por bases.
\end{abstract}

Palavras chave: acidez do solo, cerrado brasileiro, disponibilidade de fósforo, Urochloa brizantha.

\section{PRODUCTIVE ASPECTS OF MARANDU GRASS BY PHOSPHATE FERTILIZATION AT BASE SATURATION LEVELS}

\begin{abstract}
One of the main problems for the degradation of the Brazilian pastures is the lack of correction and replacement of nutrients of the soil, since these practices are common in agriculture, however neglected in pastures. The objective of this study was to evaluate the performance of the Marandu forage at doses of phosphate fertilization at the different levels of base saturation recommended for pasture. The experiment was carried out on a farm in the municipality of Gurupi-TO. The design was randomized blocks, in a $3 \times 5$ factorial arrangement, with four replications. Plants were evaluated at doses of phosphate fertilization ( 0 , 30, 60, 90 and $120 \mathrm{~kg} / \mathrm{ha}$ of $\mathrm{P}_{2} \mathrm{O}_{5}$ ) at the base saturation levels (V\%) for pastures (low $=35 \%$, suitable $=45 \%$ and high $=65 \%$ ). The variables analysed were plant height, number of tillers and forage mass. Marandu grass plants presented better response to phosphate fertilization at higher levels of base saturation.
\end{abstract}

Keywords: Brazilian Cerrado, phosphorus availability, soil acidity, Urochloa brizantha.

\section{INTRODUÇÃO}

Atualmente o Brasil possui 172 milhões de cabeças bovinas (IBGE, 2017), a maior parte dessa produção é advinda dos 190 milhões de hectares com pastagens no país (Jank et al. 2014), visto que estas são o meio mais utilizado na alimentação bovina. Dentre os diversos gêneros cultivados, o Urochloa (=Brachiaria) é o que ocupa maior área, com cerca de $77 \%$ do total (Guarda \& Guarda, 2014).

\footnotetext{
${ }^{1}$ Programa de Pós-Graduação em Produção Vegetal, Universidade Federal do Tocantins, Gurupi, Tocantins.

${ }^{2}$ Programa de Pós-Graduação em Agronomia, Universidade Federal Rural da Amazônia, Belém, Pará.; *Autor para correspondência: rubsonif@gmail.com

${ }^{3}$ Graduação em Agronomia, Universidade Federal do Tocantins, Gurupi, Tocantins.
} 
Apesar do grande número de animais criados a pasto no país, a produtividade das pastagens na maioria dos estabelecimentos é considerada baixa (Dias Filho, 2014), comumente pela degradação das pastagens. A alta quantidade de pastos degradados tem causado preocupação e chamado atenção de várias organizações, instituições e comunidade científica (Guarda \& Guarda, 2014).

Um dos principais problemas para a degradação das pastagens brasileiras é a não correção e reposição de nutrientes do solo, uma vez que essas práticas são comuns na agricultura, no entanto negligenciadas em pastagens (Martha Júnior, Vilela \& Sousa, 2007). Segundo Faria et al. (2015), o esgotamento da fertilidade do solo em virtude da ausência de calagem e adubação, é considerado como principal causa da degradação de pastagens cultivadas. Já de acordo com Possamai et al. (2014), um fator primordial é o excesso de acidez nos solos brasileiros, associados a elevados teores de alumínio.

Em pastagens a calagem do solo é realizada em função da tolerância da espécie utilizada, sendo recomendadas diferentes saturações por bases $(\mathrm{V} \%)$ em função da espécie (tolerantes, medianamente tolerantes e susceptíveis) (Sousa \& Lobato, 2004). V\% é definido como a soma de quatro cátions básicos $(\mathrm{Ca}, \mathrm{Mg}, \mathrm{K}$ e $\mathrm{Na})$ em relação à capacidade total de troca catiônica do solo $(\mathrm{Ca}, \mathrm{Mg}, \mathrm{K}, \mathrm{Na}$ e $\mathrm{H}+\mathrm{Al})$ a pH 7,0 (Bohn et al., 1979). Juntamente com a redução e ou neutralização do $\mathrm{Al}$ e fornecimento de cálcio e magnésio, a calagem permite elevação da disponibilidade de nutrientes, entre eles o fósforo que é, após o nitrogênio, o segundo nutriente que mais limita a produtividade das pastagens (Rezende et al., 2011).

O fósforo tem importancia, entre outros fatores, para o crescimento de raízes e perfilhamento, com maior influência no estabelecimento da pastagem (Faria et al., 2015; Teixeira et al., 2018). A deficiência de fósforo reduz a taxa de crescimento e a capacidade produtiva das forrageiras (Santos et al., 2006). Na maioria dos solos brasileiros o fósforo encontra-se apenas parcialmente disponível para as plantas, devido a diversas reações no solo, sendo a adsorção específica do fósforo aos óxidos de ferro e alumínio uma das principais reações ocorridas em solos tropicais (Leite et al., 2017).

Visto que a acidez do solo e a disponibilidade de fósforo para as plantas são uns dos principais fatores que limitam a produtividade em regiões tropicais. O presente trabalho teve como objetivo avaliar o desempenho da forrageira Marandu em doses de adubação fosfatada nos diferentes níveis de saturação por bases recomendados para pastagens.

\section{MATERIAL E MÉTODOS}

$\mathrm{O}$ experimento foi instalado em uma fazenda no

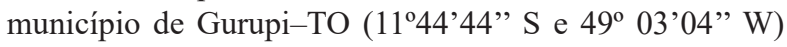
altitude média de $292 \mathrm{~m}$, durante os meses de novembro de 2009 a abril de 2010. A região é classificada como Cerrado brasileiro e apresenta um clima "Aw" (quente e úmido), de acordo com a Classificação Internacional de Köppen (Alvarez et al., 2013). O solo na área experimental apresenta textura franco-argilo-arenosa (Tabela 1), sendo classificado como Latossolo Vermelho Amarelo distrófico (Embrapa, 2018). De acordo com histórico da área a pastagem foi implantada no ano de 2003, sendo realizada correção do solo e adubação de fundação de acordo com o recomendado para a cultura, desde então, não houve qualquer tipo de adubação ou correção de manutenção na área. Os dados climáticos durante o período experimental são apresentados na Figura 1.

Tabela 1 - Parâmetros químicos e físicos do solo (camada 0-20 cm) da área experimental

\begin{tabular}{lclc}
\hline $\mathrm{pH}\left(\mathrm{CaCl}_{2}\right)$ & 5.0 & $\begin{array}{l}\text { Acidez Potencial }(\mathrm{H}+\mathrm{Al}) \\
\left(\mathrm{cmol}_{\mathrm{c}} / \mathrm{kg}\right)\end{array}$ & 3.4 \\
Matéria orgânica $(\mathrm{g} / \mathrm{kg})$ & 24.0 & $\begin{array}{l}\text { Soma de bases }(\mathrm{Ca}+\mathrm{Mg}+\mathrm{K}) \\
\left(\mathrm{cmol}_{\mathrm{c}} / \mathrm{kg}\right)\end{array}$ & 1.9 \\
Fósforo $(\mathrm{mg} / \mathrm{kg})$ & 2.4 & $\begin{array}{l}\text { Capacidade de Troca } \\
\text { Catiônica }\left(\mathrm{cmol}_{\mathrm{c}} / \mathrm{kg}\right)\end{array}$ & 5.1 \\
Potássio $(\mathrm{mg} / \mathrm{kg})$ & 63.0 & Saturação por bases $(\mathrm{V} \%)$ & 0.35 \\
Calcio $\left(\mathrm{cmol}_{\mathrm{c}} / \mathrm{kg}\right)$ & 1.0 & Areia $(\%)$ & 62.0 \\
Magnésio $\left(\mathrm{cmol}_{\mathrm{c}} / \mathrm{kg}\right)$ & 0.6 & Silte $(\%)$ & 8.0 \\
Alumínio trocável $(\mathrm{cmol} / \mathrm{kg})$ & 0.1 & Argila $(\%)$ & 30.0 \\
\hline
\end{tabular}

P e K disponíveis: extração com Mehlich-1; Ca, Mg e Al trocáveis: extração com $\mathrm{KCl} ; \mathrm{H}+\mathrm{Al}$ : extração com acetato de cálcio.

O delineamento utilizado foi blocos casualizados, em arranjo fatorial $3 \times 5$ com quatro repetições, totalizando 60 unidades experimentais de $20 \mathrm{~m}^{2}(5 \times 4)$ cada. O primeiro fator era composto por níveis de saturação por bases para pastagens: alto $(\mathrm{V} \%=65 \%)$, adequado $(\mathrm{V} \%=45 \%) \mathrm{e}$ baixo $(\mathrm{V} \%=35 \%)$, de acordo com o manual de correção e adubação para o Cerrado (Sousa \& Lobato, 2004). O segundo fator composto por doses de adubação fosfatada $\left(0,30,60,90\right.$ e $120 \mathrm{~kg} / \mathrm{ha}$ de $\left.\mathrm{P}_{2} \mathrm{O}_{5}\right)$. 


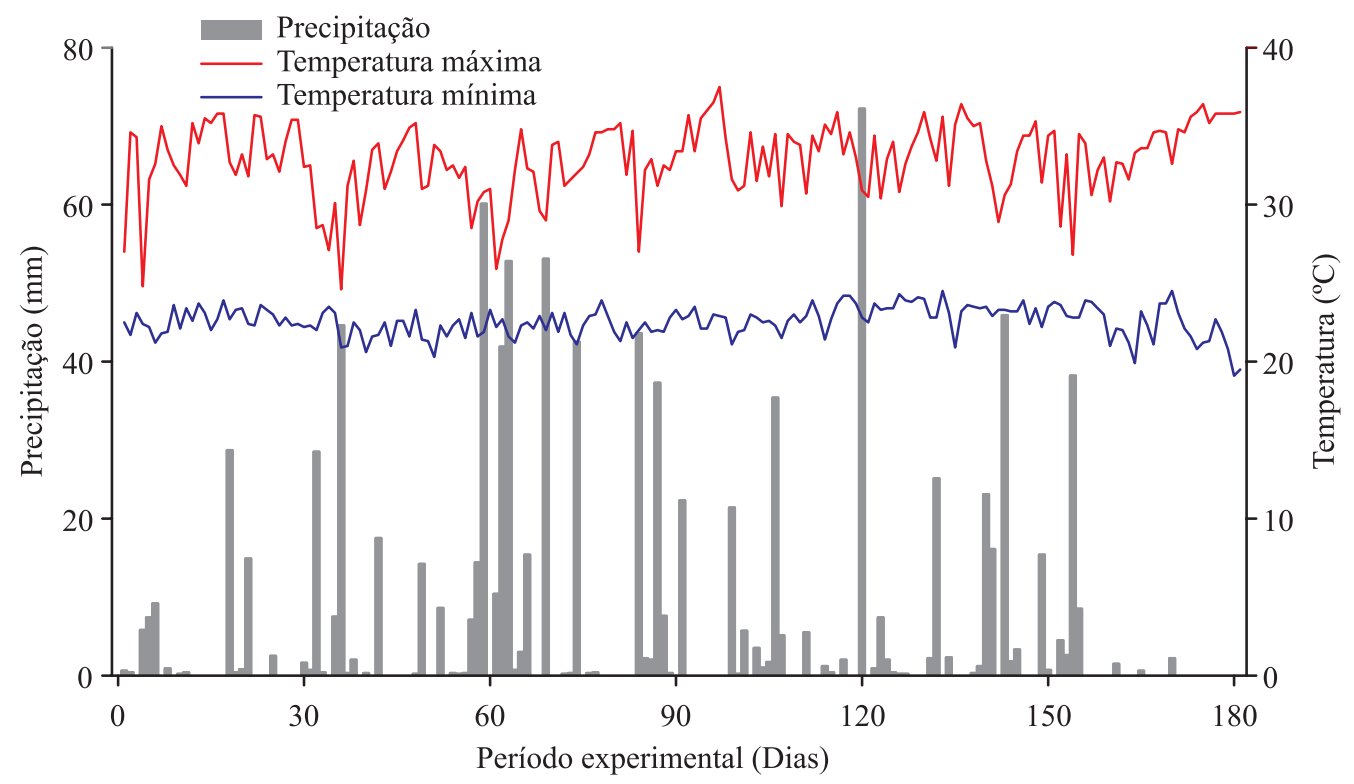

Figura 1 - Dados climáticos da área durante o período experimental.

Os diferentes níveis de $\mathrm{V} \%$ foram atingidos através da fórmula:

$$
N C=\frac{[(V 2-V 1) T] f}{100}
$$

Onde: NC: necessidade de calagem (t/ha); V2: V\% desejada; V1: V\% atual; T: capacidade de troca cationica a $\mathrm{pH} 7$; f: 100/PRNT. Assim chegou-se as doses de $0(\mathrm{~V} \%=35), 631(\mathrm{~V} \%=45)$ e $1790(\mathrm{~V} \%=65) \mathrm{kg} / \mathrm{ha}$ de calcário.

A distribuição do calcário foi realizada a lanço, atingindo toda superfície do solo da forma mais homogênea possível, não sendo realizado qualquer tipo de incorporação. O produto utilizado foi do tipo dolomítico, com 97\% de PRNT (Poder Relativo de Neutralização Total), objetivando o mais rápido possível as reações necessárias no solo. A fonte utilizada para o fornecimento de fósforo foi o superfosfato simples $\left(18 \%\right.$ de $\left.\mathrm{P}_{2} \mathrm{O}_{5}\right)$ e a aplicação foi realizada manualmente para que houvesse uma melhor distribuição do adubo dentro das parcelas, não havendo incorporação do mesmo.

Logo após a realização da calagem e da adubação foram realizados cortes de uniformização da forragem, realizado com auxílio de uma roçadeira de arrasto acoplada a um trator, deixando uma altura de resíduo de $20 \mathrm{~cm}$ do solo. 30 dias após o corte de uniformização da forrageira foram iniciadas as coletas, realizadas a cada 30 dias após o corte anterior, com altura de resíduo de $20 \mathrm{~cm}$.

Como aspectos produtivos da forrageira, foram consideradas e avaliadas as variáveis: altura de plantas, perfilhos e massa de forragem. A altura das plantas foi realizada manualmente com régua, medindo-se a partir do solo até a curvatura da última folha completamente expandida. O número de perfilhos pela contagem da quantidade de perfilhos em quadro de amostragem $(0,5 \times 0,5$ m) em quatro pontos dentro de cada parcela. Posteriormente a contagem de perfilhos dentro de cada quadro, as plantas eram cortadas a uma altura de $20 \mathrm{~cm}$ e o material coletado era identificado e levado para à estufa de circulação forçada $\left(55^{\circ} \mathrm{C}\right)$ até peso constante, sendo posteriormente pesado e determinada a massa de forragem $\mathrm{em} \mathrm{kg} / \mathrm{ha}$.

Com os resultados obtidos nas avaliações das variáveis durante quatro cortes de avaliação, os valores de cada corte foram submetidos à análise de regressão, avaliando-se a significância dos betas e os coeficientes de determinação para obtenção do modelo de regressão adequado.

\section{RESULTADOS}

De acordo com a análise de regressão, houve ajuste ao modelo de regressão em todas as variáveis analisadas, sendo que apenas no $4^{\circ}$ corte da variável massa 
de forragem, nenhum dos níveis de saturação testados apresentaram ajuste a regressão em função das doses de fósforo aplicadas.

Para altura de plantas houve ajuste ao modelo de regressão em todos os cortes avaliados (Figura 2). Sem adubação fosfatada (dose zero de fertilizante) ocorreu baixa amplitude de diferença entre os níveis de saturação avaliados. No entanto com o fornecimento de fósforo é possível observar o aumento na altura de plantas em ambos os níveis de saturação, sendo mais evidenciado a partir do $2^{\circ}$ corte.

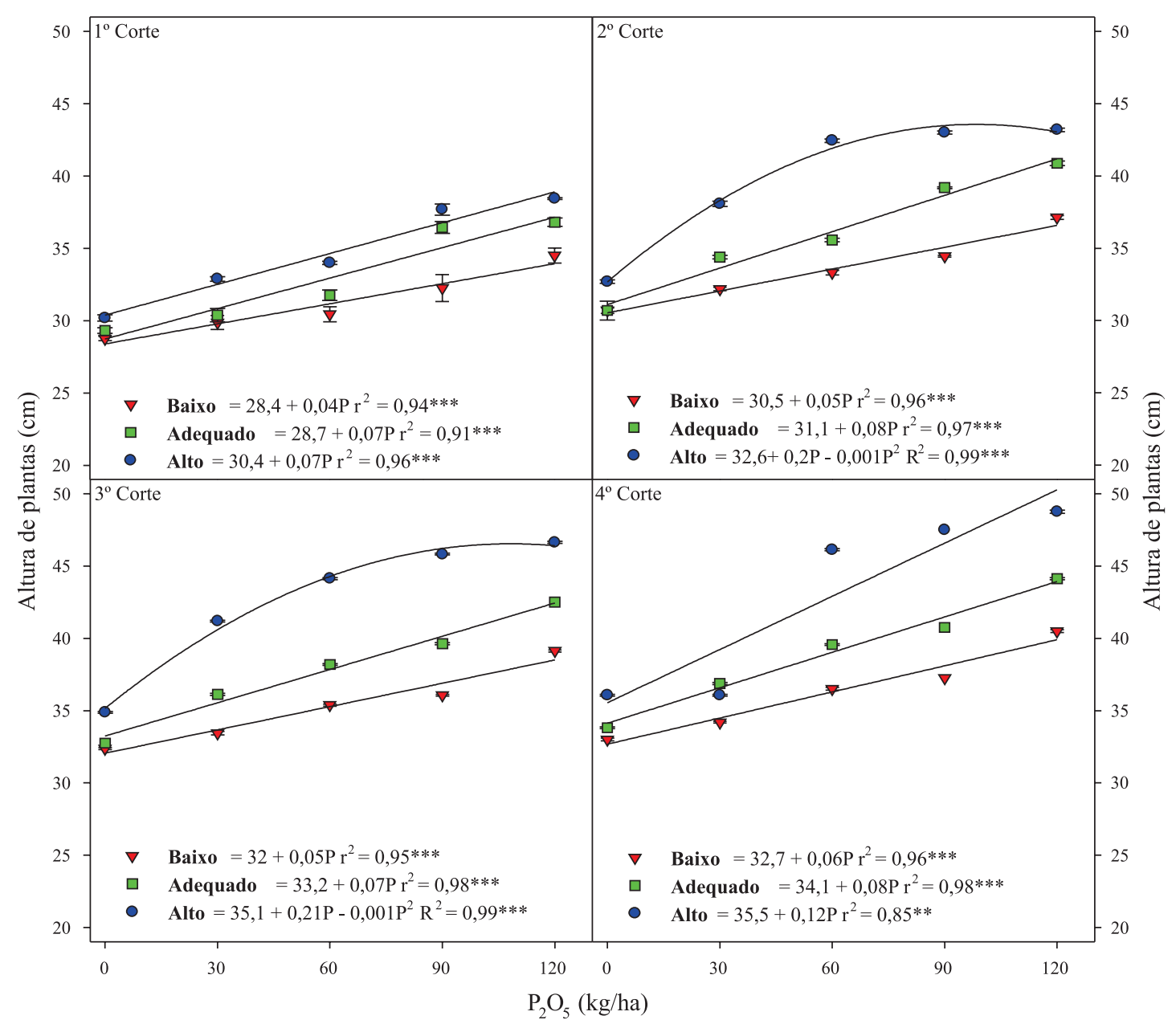

Figura 2 - Altura de plantas de capim Marandu sob doses de adubação fosfatada em níveis de saturação por bases.

Para o primeiro corte em todos os níveis de saturação por bases observados, houve ajuste a regressão linear positiva até a maior dose de $\mathrm{P}_{2} \mathrm{O}_{5}$ fornecida (Fig. 2). Já o segundo e terceiro corte apresentou ajuste a regressão quadrática em alto nível de saturação por bases, semelhante ocorreu ao terceiro corte de avaliação.
No $4^{\circ}$ corte de avaliação, ambos os níveis apresentaram ajuste ao modelo linear, sendo que foram alcançadas alturas de 40, 44 e $50 \mathrm{~cm}$, respectivamente para o nível baixo, adequado e alto.

Com relação a produção de perfilhos, todos os cortes avaliados apresentaram ajuste ao modelo de 
regressão linear (Figura 3). Nos dois primeiros cortes, apesar de haver aumento de perfilhos em função da dose de fósforo fornecida, os níveis de saturação por base tiveram modestas diferenças para a variável.

A partir do terceiro corte, as plantas continuaram a apresentar acréscimo no número de perfilhos em função do aumento da adubação fosfatada e para os níveis de $\mathrm{V} \%$, valores mais expressivos foram encontrados a partir da dose de $90 \mathrm{~kg} /$ ha de $\mathrm{P}_{2} \mathrm{O}_{5}$. Ao final do experimento $\left(4^{\circ}\right.$ corte) o comportamento foi mantido.

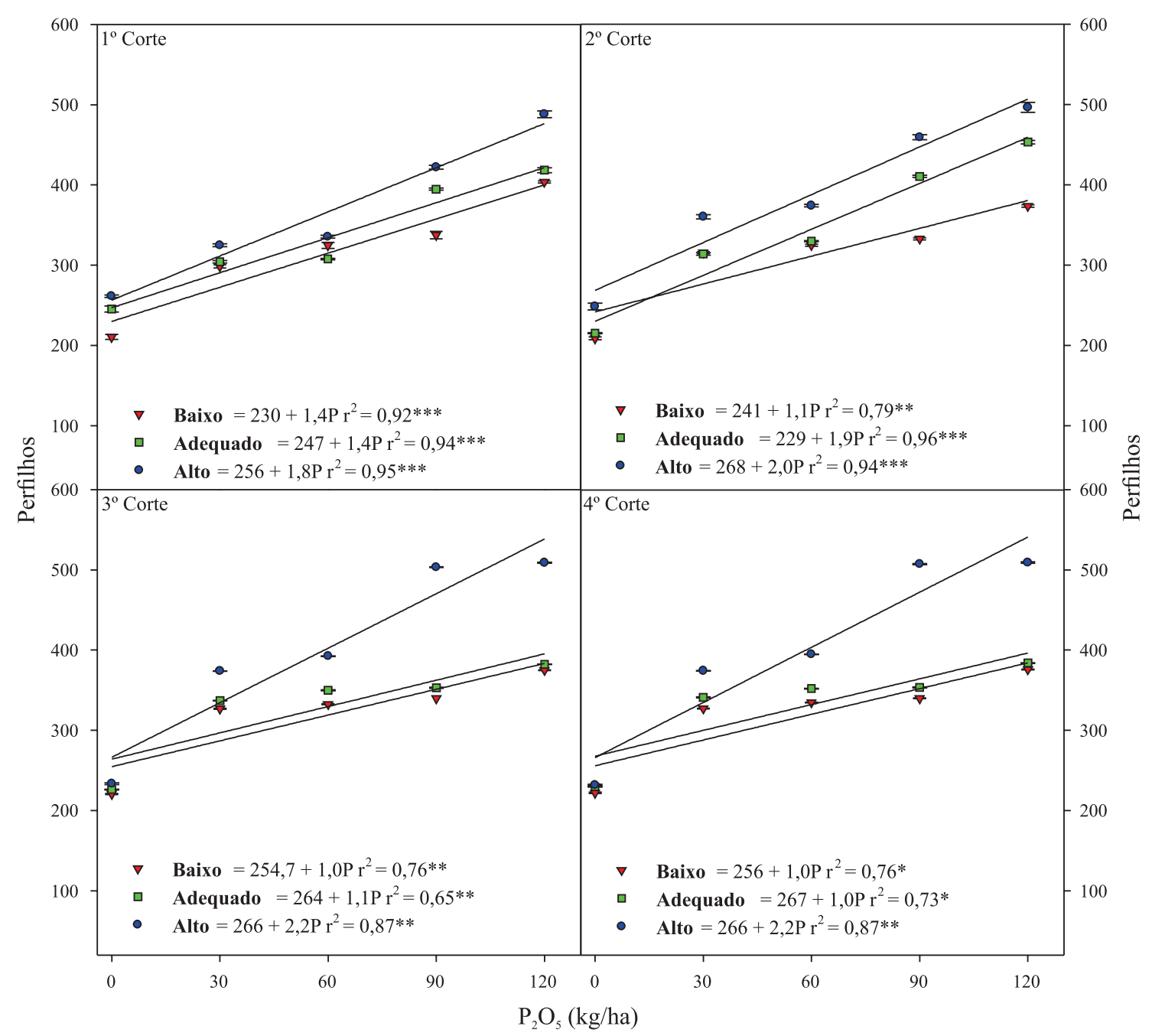

Figura 3 - Número perfilhos de capim Marandu sob doses de adubação fosfatada em níveis de saturação por bases.

No quarto corte de avaliação, ao comparar a maior dose $(120 \mathrm{~kg} / \mathrm{ha})$ de fonte de fósforo fornecida, a produção de perfilhos foi de 370,387 e 530 perfilhos, respectivamente para níveis baixo, adequado e alto de saturação por bases.

Para a massa de forragem, houve ajuste ao modelo de regressão para os três primeiros cortes (Figura 4). Até o terceiro corte as plantas responderam de forma positiva ao aumento da adubação fosfatada. No quarto corte avaliado as plantas não se ajustaram ao modelo de regressão em nenhum dos níveis de saturação avaliados.

Ao comparar os maiores resultados para massa de forragem em função da dose de fertilizante fosfatado 
fornecido nos diferentes níveis de V\%, no primeiro corte houve acréscimo de 10 e $69 \%$, respectivamente para os níveis adequado e alto em comparação ao nível baixo de V\%. Para o segundo e terceiro corte o nível alto continuou a manter-se superior em relação aos outros níveis avaliados, no entanto com menor nível de acréscimo.

No quarto corte de avaliação a diferença para massa de forragem em função dos níveis de V\% aplicados foi pouco expressiva.

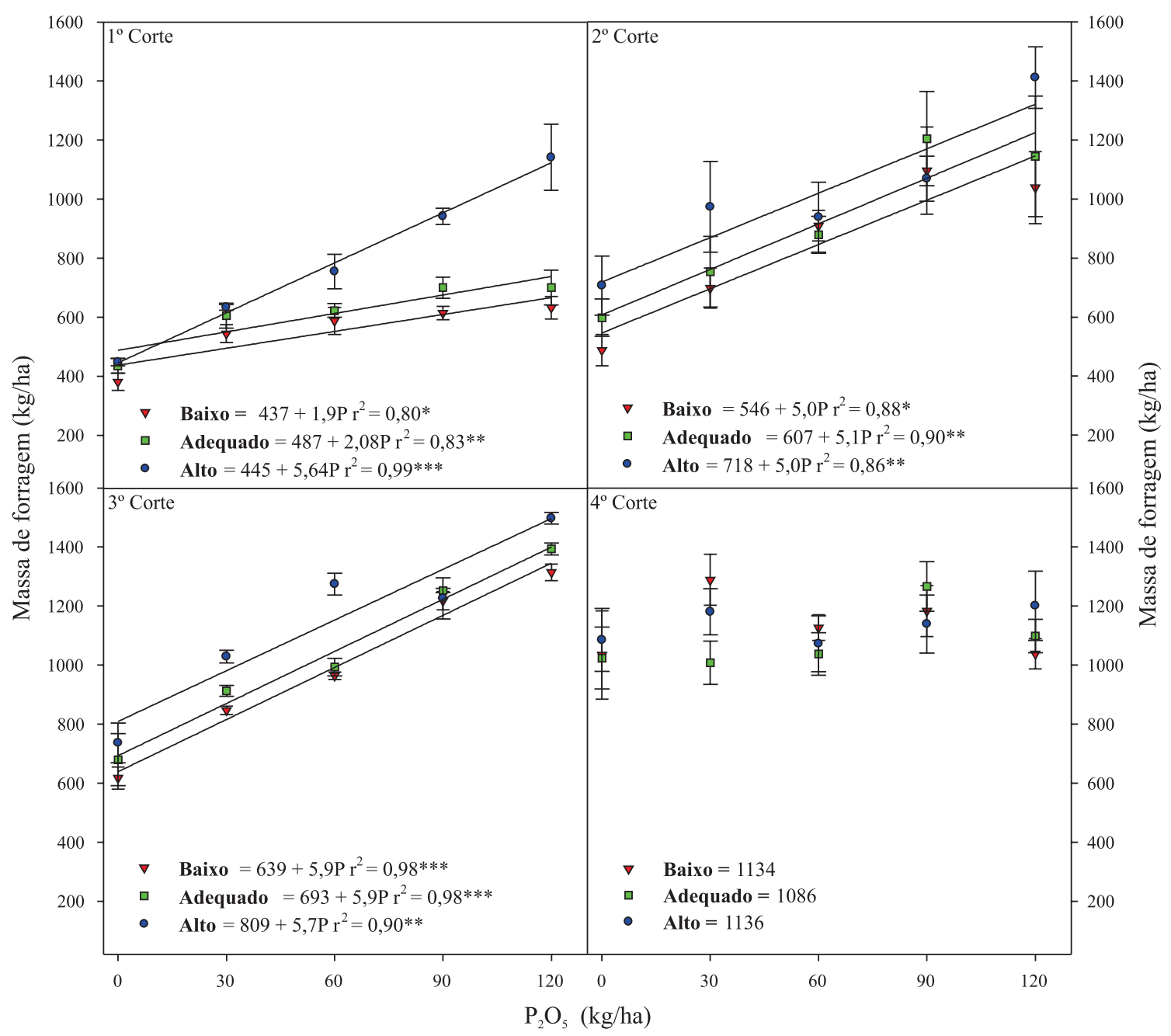

Figura 4 - Massa de forragem de capim Marandu sob doses de adubação fosfatada em níveis de saturação por bases.

\section{DISCUSSÃO}

Os resultados apresentados nas figuras 1 e 2 demonstram ter havido resposta para variáveis altura de plantas e número de perfilhos em plantas de capim Marandu em função da adubação fosfatada e que a melhor resposta foi encontrada quando o nível de saturação por bases se encontrava alto para a cultura $(65 \%)$, isso demonstra que apesar da tolerância mediana da cultura, a disponibilidade de nutrientes como fósforo pode afetar a produção e eficiência do fertilizante aplicado. Mesmo em culturas tolerantes à acidez elevada do solo, tem-se de considerar o benefício da correção da acidez na disponibilidade de nutrientes como fósforo, pois a correção da acidez é uma prática que contribui para aumentar a disponibilidade de $\mathrm{P}$ do solo e a eficiência dos fertilizantes fosfatados (Sousa \& Lobato, 2003). 
A carência de fósforo no solo traz prejuízos ao desenvolvimento radicular, perfilhamento e estabelecimento das pastagens, o que resulta em baixa produtividade e capacidade de suporte animal (Carneiro et al., 2017). Este nutriente é responsável ainda pelo bom desenvolvimento de plântulas no início do seu desenvolvimento (Santos et al., 2015; Leite et al., 2017).

Em todos os quatro cortes avaliados as plantas responderam de forma positiva ao aumento no número de perfilhos em função de acréscimo na adubação fosfatada. Este nutriente é comumente utilizado na adubação de estabelecimento, atuando no metabolismo das plantas, na fotossíntese, respiração, metabolismo de açúcares, divisão celular e alargamento das células (Faria et al., 2015).

No último corte avaliado, o número de perfilhos foi aumentado em $43 \%$ na melhor dose em alto nível de saturação, em comparação a mesma dose em nível baixo. Em gramíneas forrageiras, o perfilhamento tem importancia para produção de biomassa e representa uma das mais importantes características para o estabelecimento das plantas e da produtividade de pastagens (Faria et al., 2015). O aumento do número de perfilhos promove maior cobertura do solo, o que pode mitigar problemas de erosão em pastagens, problema que também contribui para degradação dessas. Uma das suas principais funções do uso de forrageiras quanto à conservação do solo é a de minimizar o impacto da gota de chuva diretamente no solo, evitando a desagregação das partículas (Araújo, 2015).

Houve aumento de produção em função da adubação fosfatada até o terceiro corte. Esse aumento de produção pode estar relacionado ao aumento no número de perfilhos, pois, segundo Faria et al. (2015), o aumento no número de perfilhos de gramíneas forrageiras promove um maior incremento na produção de massa seca das pastagens.

Nossos estudos representam os períodos iniciais na recuperação de uma pastagem, possivelmente os benefícios da elevação dos níveis de saturação por bases se tornem mais evidentes em um períodos mais longo de avaliação pela disponibilidade de nutrientes, especialmente o fósforo aplicado. Nosso próximo passo será investigar os benefícios da elevação de saturação por bases na disponibilidade do fósforo para recuperação de pastagens em um maior período de avaliação.

\section{CONCLUSÃO}

Plantas de capim Marandu respondem positivamente a elevação dos níveis de saturação por bases. Estas apresentam melhor resposta a adubação fosfatada nos maiores níveis testados.

\section{LITERATURA CITADA}

ALVAREZ, C.A.; STAPE, J.L.; SENTELHAS, P.C.; GONCALVES, J.L.M.; SPAROVEK, G. Koppen's climate classification map for Brazil. Meteorologische Zeitschrift, v.22, n.6, p.711-728, 2013. doi: https://doi. org/10.1127/0941-2948/2013/0507

ARAÚJO, A.R. Conservação do solo e da água para pastagens tropicais - uma abordagem sistêmica. Embrapa Gado de Corte. 2015. Disponível em: https://www.embrapa. br Acesso em: 10/05/2018.

BOHN, H.L.; MCNEAL, B.L.; O'CONNOR, G.A. Soil Chemistry. John Wiley and Sons, Toronto, Canada. 1979.

CARNEIRO, J.S.S.; SILVA, P.S.S.; SANTOS, A.C.M.; FREITAS, G.A.; SILVA, R.R. Resposta do capim Mombaça sob efeito de fontes e doses de fósforo na adubação de formação. Journal of Bioenergy Food Science, v.4, n.1, p.12-25, 2017. https://doi.org/10.18067/jbfs.v4i1.117

DIAS-FILHO, M.B. Diagnóstico das pastagens brasileiras. Documentos 402. Belém: Embrapa Amazônia Oriental, 2014. 36p.

EMBRAPA(Empresa Brasileira de Pesquisa Agropecuária). Sistema Brasileiro de Classificação de solos. $5^{\text {a }}$ edição. Brasília-DF, 2018. 590p.

FARIA, A.J.G.; FREITAS, G.A.; GEORGETTI, A.C.P.; FERREIRA JÚNIOR, J.M.; SILVA, M.C.A.; SILVA, R.R. Efeitos da adubação nitrogenada e potássica na produtividade do capim Mombaça cultivados sobre adubação fosfatada. Journal of Bioenergy and Food Science, v.2, n.3, p.98-106, 2015.

GUARDA, V.D.A.; GUARDA, R.D.A. Brazilian tropical grassland ecosystems: distribution and research advances. American Journal of Plant Science, v.5, n.7, p.924-932, 2014. http://dx.doi.org/10.4236/ajps.2014.57105

IBGE (Instituto Brasileiro de Geografia e Estatística). Pesquisa da Pecuária Municipal-Ano de 2017. Disponível em: https://www.ibge.gov.br. Acesso em: 12/06/2019.

LEITE, R.C.; CARNEIRO, J.S.S.; FREITAS, G.A.; CASALI, M.E.; SILVA, R.R. Adubação fosfatada na soja durante três safras consecutivas na nova fronteira agrícola brasileira. Scientia Agraria, v.18, n.4, p.28-35, 2017.

MARTHA JÚNIOR, G.B.; VILELA, L.; SOUSA, D.M.G. Cerrado: uso eficiente de corretivos e fertilizantes em pastagens. Planaltina, DF: Embrapa Cerrados, 2007. 224p.

POSSAMAI, A.J.; FREIRIA, L.B.; BARBOZA, A.C.; ROSA E SILVA, P.I.J.L.; ZERVOUDAKIS, J.T. Influência 
da adubação fosfatada e calagem na ecofisiologia de gramíneas forrageiras. PUBVET, v.8, n.8, p.257, 2014.

REZENDE, A.V.; LIMA, J.P.; RABELO, C.H.S.; RABELO, F.H.S.; NOGUEIRA, D.A.; CARVALHO, M.; FARIA JUNIOR, D.C.N.A.; BARBOSA, L.A. Características morfofisiológicas da Brachiaria brizantha cv. Marandu em resposta à adubação fosfatada. Revista Agrarian, v.4, n.14, p.335-343, 2011.

SANTOS, A.C.M.; CARNEIRO, J.S.S.; LEITE, R.C.; SOUZA, M.A.S.; FREITAS, G.A.; SILVA, R.R. Adubação fosfatada com fertilizante Basiduo ${ }^{\circledR}$ na cultura da soja no oeste da Bahia. Journal of Bioenergy and Food Science, v.2, n.3, p.82-90, 2015.

SANTOS, I.P.A.; PINTO, J.C.; FURTINI NETO, A.E.; MORAIS, A.R.; MESQUITA, E.E.; FARIA,
D.J.C.; ROCHA, G.P. Frações de fósforo em gramíneas forrageiras tropicais sob fonte e doses de fósforo. Ciência e Agrotecnologia, v.30, p.961-970, 2006.

SOUSA, D.M.G.; LOBATO, E. Adubação fosfatada em solos da região do Cerrado. Encarte técnico. Informações agronômicas n ${ }^{\circ}$ 102, 2003.

SOUSA, D.M.G.; LOBATO, E. Cerrado: Correção do solo $e$ adubação. Embrapa Informação Tecnológica. Brasília, DF, BRA. 2004. 416p.

TEIXEIRA, S.O.; TEIXEIRA, R.O.; SANTOS, V.B.; CARVALHO, M.A.C.; YAMASHITA, O.M. Doses de fósforo e nitrogênio na produção de Brachiaria hibrida cv. Mulato II. Revista Ceres, v. 65, n.1, p. 028-034, 2018. http://dx.doi.org/10.1590/0034-737X201865010005

Recebido para publicação em 23/07/2019 e aprovado em 04/02/2020. 